Revista Brasileira

de Estudos de

Cinema

e Audiovisual

\title{
Producción, mercados y políticas \\ públicas cinematográficas en América Latina
}

Film production, market and public

policies in Latin America

Roque González 1

${ }_{1}^{1}$ Consultor del Instituto de Estadísticas de la Unesco. Autor de dos libros, capítulos en compilaciones y decenas de artículos y papers sobre cine, audiovisual e industrias culturales, publicados en Estados Unidos,

España, Italia, México, Brasil, Argentina y Colombia (como "Emerging Markets and the Digitalization of the Film Industry", Institute of Statistics, UNESCO, Montreal, 2013, entre otros). Conformó, junto a Octavio Getino, el Observatorio del Cine y el Audiovisual Latinoamericano (Ocal-FNCL) y el Observatorio del Mercosur Audiovisual (OMA-Recam). Referente latinoamericano del Observatorio Europeo del Audiovisual. 


\section{Resumen}

Desde hace 20 años - luego del período neoliberal (basado en los postulados del Consenso de Washington) - las políticas públicas de cinematografía en América Latina se encuentran enfocadas casi exclusivamente en la producción. La comercialización, la convergencia audiovisual y la digitalización están prácticamente ausentes en estas políticas. En este contexto, dos intentos de regionalizar políticas públicas cinematográficas tuvieron distintos abordajes y resultados.

Palabras clave: Políticas públicas cinematográficas; producción; distribución; exhibición

\section{Resumo}

Durante os últimos 20 anos -depois do período neoliberal (baseado nos postulados do Consenso do Washington) - as políticas públicas de cinema na América Latina estão enfocadas quase exclusivamente na produção. Neste contexto, duas tentativas para fazer políticas públicas cinematográficas latino-americanas tiveram diferentes abordagens e resultados.

Palavras-chave: Políticas públicas cinematográficas; produção; distribução; exhibição

\section{Abstract}

For the last 20 years--since the neoliberal period of the 1990s (based on Washington Consensus)--public policies on cinematography in Latin America have focused predominantly on production. In this context, two (intentos) to make public film policies in Latin America had different (abordajes) and (results).

Keywords: Film policies; production; distribution; exhibition. 
Revista Brasileira

de Estudos de

Cinema

e Audiovisual

El presente trabajo busca analizar la producción y los mercados cinematográficos en América Latina en los últimos años, en el contexto de las políticas públicas de fomento a esta actividad.

Durante la última década dichas políticas fueron retomando fuerza -en casos como el argentino, mexicano y brasileño- o comenzaron a surgir -por ejemplo, en Colombia, Chile, Uruguay y Ecuador, entre otros países-. Por otra parte, éstas políticas buscaron expandirse a nivel regional - por ejemplo, en los casos de la Conferencia de Autoridades Cinematográficas de Iberoamérica (Caci) y de la Reunión Especializada de Autoridades de Cine y Audiovisual del Mercosur (Recam).

La presente investigación se enmarcará en el mencionado campo de la Economía Política de la Comunicación y la Cultura (EPCC), y más específicamente, en la Economía Política del Cine.

La EPCC estudia el rol del poder en la producción, en la distribución especialmente, en este punto (PENDAKUR, 1990; BALIO, 1993; WASKO, 2011) - y en el intercambio de la comunicación mediada, analizando las relaciones sociales, las estructuras del poder, el proceso por el cual los mensajes se transforman en mercancías y las relaciones entre producción material y producción intelectual. A nivel más básico, la EPCC estudia la manera en que la comunicación y la cultura formen parte del proceso de acumulación de capital, de la estratificación y las desigualdades de clases y de las relaciones entre los centros de poder político y los centros de poder económico (Guback, 1980; Pendakur, 1990; Wasko, 2003; Getino, 2005; Sánchez Ruiz, 2012).

Según la economía política del cine, las películas son mercancías producidas y distribuidas dentro de una estructura industrial capitalista (Guback, 1980; Wasko, 2003, 2011), concentrada, con una asimétrica división internacional del trabajo audiovisual (Miller y Yúdice, 2004, se refieren a la "nueva división internacional del trabajo cultural"), en el marco de relaciones de poder dentro del sistema cultural y político, con el agregado de que el cine es a la vez producto y servicio intangible (Pendakur, 1990), importante no sólo por su valor de cambio sino por su valor cultural (Pendakur, 2003; Getino 2005) -en cuanto elemento trascendente para la constitución de la identidad y la cultura de un pueblo. 
El presente trabajo parte del criterio de que el cine en América Latina durante la última década se caracterizó por el regreso del apoyo estatal al cine ("neofomentismo") - luego del desmantelamiento de las ayudas públicas a este sector hacia fines de la década de 1980 y comienzos de la de ' 90 , enfatizando en la producción.

A su vez, esta reflexión busca mostrar que el sector cinematográfico en América Latina sólo puede existir por el fomento estatal, debido a que tienen nula recuperación de los costos a través de la taquilla en sus respectivos mercados nacionales -y menos aún en los mercados internacionales, en donde prácticamente no circula.

A esta situación se suma la posición oligopólica en el mercado de la distribución y la exhibición por parte de las majors de Hollywood - tanto en Estados Unidos como en el resto del mundo (salvo contadas excepciones, como China e India).

A continuación se profundizará en estos temas, aclarando que las variadas estadísticas y números de producción y mercado fueron realizados por el autor de este artículo, basándose en datos oficiales, información de empresas del sector y de medios periodísticos (salvo cuando se especifique la fuente).

\section{Producción y mercados}

Desde hace algunos años en América Latina se producen entre 300 y 350 largometrajes anuales (con picos de 400, en 2008), un número notablemente superior al de las décadas recientes: durante los años ochenta se produjo un promedio de 230 largometrajes anuales, y durante los noventa, ese promedio bajó a 91 producciones al año (GONZÁLEZ, 2012: 95).

Durante el último decenio, la producción cinematográfica en varios países de la región ha alcanzado picos históricos. El fomento estatal a la producción cinematográfica existente en casi toda América Latina ha permitido el aumento en la producción de películas como nunca antes en la región; inclusive en países como México, Brasil y Argentina el número de filmes realizados alcanza valores que sólo se habían conseguido décadas atrás. 
Revista Brasileira

de Estudos de

Cinema

e Audiovisual

América Latina produjo en total alrededor de 4500 largometrajes en el período 2000-20132. La decidida acción del fomento estatal en la mayoría de los países latinoamericanos se vio reflejada en la cantidad de largometrajes producidos. Sin embargo, a pesar de estos incrementos, en ningún país latinoamericano se termina de configurar una "industria", sino sólo un ecosistema fragmentado en el que conviven algunas pocas empresas profesionales con innumerables pequeños emprendimientos sin sustentabilidad, atomizados e inconexos, con el peso puesto - tanto desde el sector público como en el privado- en la producción más no en la comercialización y exhibición de los filmes nacionales.

Por su parte, la coproducción internacional se convirtió, en las últimas décadas, en una importante estrategia para hacer frente a obstáculos como el difícil financiamiento y las dificultades para que los filmes circulen más allá de las fronteras nacionales. Para varios países de la región la coproducción fue fundamental para revitalizar y fortalecer su sector cinematográfico, como en los casos de Cuba, Bolivia y Uruguay.

\section{Comercialización}

Si los latinoamericanos -que en promedio concurren 0,8 veces al cine al año- tuvieran una circulación cinematográfica regional verdaderamente eficiente, tendrían -en teoría - entre 400 y 550 filmes regionales anuales entre los cuales escoger -dependiendo el país-. Sin embargo, ello no ocurre: anualmente se estrenan entre 3 y 20 filmes latinoamericanos no nacionales -dependiendo del país -, cuyo público suele ser menor al 1\% del total de los espectadores de cine (GONZÁLEZ, 2012: 107).

En 2013 se vendieron en América Latina 581 millones de entradas -que en promedio cuestan 5,5 dólares cada una- para asistir a alguna de las 11.300

\footnotetext{
2 Elaboración propia basada en datos de las agencias nacionales de cine de Argentina, Brasil, México, Colombia, Chile, Perú, Uruguay, Venezuela, Bolivia, Ecuador, de las consultoras Rentrak, Ultracine y medios especializados.
} 
salas existentes en el subcontinente para elegir entre los 210 estrenos que, en promedio, se estrenan anualmente. ${ }^{3}$

A su vez, en el mismo año América Latina sumó casi 2.700 millones de dólares de recaudación por entradas de cine $-2,7$ billones de dólares, según la nomenclatura anglosajona que en América Latina utiliza Brasil. ${ }^{4}$ Esta cifra se debe, principalmente, al constante aumento de las entradas-que duplicó su precio durante el último decenio (en los últimos dos años empujado por los precios premium de las salas 3D) - y a la alta inflación registrada en los últimos años en Argentina y Venezuela -estos países se encuentran entre los países con mayores tasas de inflación del mundo.

Como ejemplo de lo anterior: la revista Variety, en un artículo del 6 de abril de 2013, llegó a publicar con bombos y platillos que el box office argentino tuvo en 2012 un crecimiento interanual del 35\%; pero esta apreciación olvidó de tomar en cuenta la mencionada inflación argentina.

Analizando los resultados de 2012 para Argentina y Venezuela, se aprecia - en efecto- un aumento interanual del 35\% tanto para la recaudación argentina -tomando en cuenta todas las películas exhibidas, no sólo los estrenos- como para la venezolana. Sin embargo, si se observa el aumento de espectadores para los años 2011-2012, en Argentina el crecimiento fue de tan sólo el $6 \%$ y en Venezuela no hubo ningún crecimiento: se vendió la misma cantidad de entradas (alrededor de 30 millones). En 2013 las disparidades de aumento entre la cantidad de espectadores y la recaudación fueron similares.

\footnotetext{
${ }^{3}$ Elaboración propia basada en datos de las agencias nacionales de cine de Argentina, Brasil, México, Colombia, Chile, Perú, Uruguay, Venezuela, Bolivia, Ecuador, de las consultoras Rentrak, Ultracine, de distribuidoras, exhibidoras y medios especializados.

${ }^{4}$ Elaboración propia basada en datos de las agencias nacionales de cine de Argentina, Brasil, México, Colombia, Chile, Perú, Uruguay, Venezuela, Bolivia, Ecuador, de las consultoras Rentrak, Ultracine, de distribuidoras, exhibidoras y medios especializados.
} 
Revista Brasileira

de Estudos de

Cinema

e Audiovisual

\section{Concentración en la exhibición}

Durante la década del 2000 se consolidó la concentración elitista del mercado cinematográfico, que prepondera las ciudades y las zonas más ricas, a la vez que a las clases más pudientes, para consolidar el incremento sostenido en las taquillas con menos diversidad en las pantallas y de espaldas a las masas que sustentan la base de la pirámide social.

En efecto: entre las décadas del ochenta y el noventa cerraron casi la mitad de las salas de cine que había en América Latina (GETINO, 2005: 82). La mayoría de ellas se encontraba en el interior de los países, que es donde históricamente siempre se vio más cine nacional. Actualmente, existen en la región entre 5 y 20 salas de cine -40 en el caso de México- por cada millón de habitantes -tres veces menos que hace tres décadas (GONZÁLEZ, 2012: 119).

De esta manera, el incremento del $65 \%$ promedio que el parque exhibidor regional mostró en la década del 2000 -empujado por México, Brasil y Colombia (en el resto de los países, la cantidad de salas casi no ha variado) - hay que ubicarlo en el contexto de una alta concentración geográfica y clasista y del alto costo de las entradas, que representan -considerando una única salida familiar al cine- alrededor del $10 \%$ del ingreso mensual medio latinoamericano (GONZÁLEZ, 2012: 120).

En este escenario aparece el cine digital a través de su nave insignia: el 3D. Hacia finales de 2008, y especialmente desde 2009, comenzaron a abrirse decenas de salas con proyección digital de alta gama (2K de resolución mínima $\left.{ }^{5}\right)$.

Todas estas salas digitales están equipadas para exhibir películas tridimensionales, la gran esperanza de las multinacionales y las grandes compañías de la industria cinematográfica, para incrementar la asistencia a las salas y, sobre todo, para elevar la recaudación: debido a que las entradas para ver películas en 3D cuestan un 30\% más, desde 2009 y 2010 se apreció como tendencia firme que aproximadamente el $10 \%$ de los estrenos -filmes hollywoodenses en tercera dimensión dirigidos al público infanto-juvenil- significan alrededor

5 "K" equivale, en este caso, a 2 elevado a 10 (sistema binario), es decir, 1024 píxeles de resolución. Se denominan 2K y 4K a imágenes de 2048 × 1080 píxeles y 4096 × 2160 píxeles, respectivamente, destinadas a proyectores $y$ archivos de cine digital. 
Revista Brasileira

de Estudos de

Cinema

e Audiovisual

del $40 \%$ de la taquilla - situación que se da tanto en América Latina como en el mundo (GONZÁLEZ, 2011: 142).

Sin embargo, las promesas que circundan alrededor del cine digital sobre democratización, abaratamiento de costos y mayor diversidad, entre otras, están quedando en la teoría: si bien el cine digital reduce considerablemente los costos por copias -cada copia en 35 milímetros cuesta entre 1500 y 2000 dólares - , la instalación de estas salas digitales - que engloban proyector, periféricos, sistema operativo, equipamiento para exhibir en tercera dimensión y en algunos casos, hasta una pantalla distinta - ronda en América Latina casi el doble que en el "Primer Mundo". En la práctica, la digitalización la están pudiendo cubrir las empresas exhibidoras más grandes, mientras que las "independientes"-empresas pequeñas, locales, suburbanas, que generalmente programan cine nacional, iberoamericano, mundial de calidad, corren serio riesgo de tener que cerrar, o ser cooptadas por las más grandes.

\section{La presencia del cine nacional en América Latina}

La difícil situación por la que atraviesan gran parte de los cines nacionales en América Latina -sobre todo en el sentido de su muy escasa llegada al público y de su poca sustentabilidad (salvo contadísimas excepciones) - no se basa en la cantidad de producciones realizadas sino en la distribución y en la exhibición. Justamente, estos eslabones de la cadena de valor audiovisual están profundamente descuidados por los Estados latinoamericanos - como también ocurre en otras regiones del mundo, como la Unión Europea (a pesar de sus abultados fondos de ayuda, destinados mayormente a la producción cinematográfica).

Las diez películas más vistas - casi en su totalidad blockbusters de Hollywood (9 de 10 en casi toda América Latina) - suelen representar en Latinoamérica entre el $35 \%$ y el $50 \%$ del total, tanto de espectadores como de recaudación en los distintos mercados. A su vez, los filmes de Hollywood concentran desde el $80 \%$ de los espectadores y taquilla en los distintos mercados latinoamericanos -en algunos mercados este porcentaje excede el $90 \%$. 
Revista Brasileira

de Estudos de

Cinema

e Audiovisual

Por su parte, la presencia de los filmes nacionales en las pantallas latinoamericanas varía de acuerdo a la capacidad, la tradición cinematográfica y las políticas de fomento de cada país.

Aunque las políticas públicas de cine hayan incrementado la producción del mismo durante la década, las audiencias de los distintos filmes nacionales son muy bajas, las películas nacionales alcanzan un market share de entre el $1 \%$ y el $15 \%$ de los espectadores según la capacidad productiva de cada país y la coyuntura -algún éxito esporádico. En el caso de los países de mayor desarrollo cinematográfico, como Argentina, Brasil y México fluctúa entre el $5 \%$ y el $15 \%$-salvo años excepcionales, en que ese market share puede acercarse al 16\%-18\%. En el resto de los países, ese porcentaje ronda entre el 1\% y el 5\% (GONZÁLEZ, 2012: 124), salvo excepciones. Esta nula presencia del cine latinoamericano en las pantallas de los mismos países es una constante en los últimos 25 años en toda la región.

Durante la última década la oferta de cine nacional se ha incrementado notablemente en los casos de Argentina, México y Brasil, duplicando en el primer caso, y triplicando en los dos restantes el número de películas nacionales estrenadas. Chile, Colombia y Perú también han visto incrementar su producción cinematográfica notablemente (de entre 5 y 10 en el año 2000 a entre 35 y 50 en 2013) -en el caso de los dos primeros, fueron muy importantes las legislaciones nacionales de fomento al cine aprobadas en la década de 2000; en el caso peruano, se destaca una importante producción en el interior del país, por fuera de los circuitos oficiales. El resto de los países ha mostrado una tendencia a incrementar levemente el número de estrenos locales (GONZÁLEZ, 2012: 125).

Las majors son las distribuidoras con mayor presencia entre los "Top 10" $-\mathrm{y}$, por lo tanto, son las empresas que se llevan la mayor parte de la torta en las recaudaciones de toda América Latina.

A pesar de que se puede suponer que las distribuidoras nacionales comercializan preferentemente filmes nacionales (UNESCO, 2007: 6), ello no ocurre en la cinematografía latinoamericana con mayor potencial de convocatoria. "Stefan vs Kramer", que en 2012 resultó el segundo filme más visto en su país, fue comercializado por Fox, mientras que "Nosotros los nobles", que por 
algunos meses de 2013 fue el filme mexicano más visto de toda la historia, se distribuyó por la Warner. "Metegol", la animación de Juan José Campanella (producida en gran parte por el canal de televisión Telefé, que a su vez, pertenece a Telefónica), fue la película argentina más vista en ese país durante 2013: se distribuyó por UIP. Al mismo tiempo, los filmes argentinos más taquilleros ese año se distribuyeron por Fox y Disney -ésta última major está teniendo una participación destacada en la distribución de filmes argentinos con potencialidad de ser "taquilleros" desde hace algunos años (especialmente, a partir de las erráticas políticas del gobierno argentino: intentando ayudar al cine nacional, el kirchnerismo exigió a las majors que comercializaran cine argentino; Hollywood terminó distribuyendo contados estrenos nacionales, los más taquilleros, hiriendo gravemente el reducido puñado de distribuidoras argentinas dedicadas al cine local).

"Tesis sobre un homicidio" también se ubicó en otro "Top 10": en el uruguayo, se distribuyó también por Disney, mientras que "Metegol" y "Séptimo" (una coproducción argentino-española protagonizada por Ricardo Darín) fueron estrenadas en Chile por la Warner. Retomando una ironía de Octavio Getino, la integración regional pareciera que está siendo abordada por empresas extranjeras... (GETINO, 2000).

Aunque no hubo variación en el número total de estrenos comerciales la hubo en incrementos significativos en la cantidad de películas nacionales estrenadas comercialmente en Perú, Colombia, Uruguay y Perú, aunque - como lamentablemente sucede desde hace más de veinte años a nivel regional- el público no sigue las producciones nacionales, salvo en contadas excepciones -unas dos o tres películas nacionales explican alrededor del 90\% de los resultados de mercado de todos los estrenos locales: esta situación se produce en toda América Latina.

Los porcentajes del market share durante 2012 se ubicaron en los números habituales que se vienen dando desde hace años: entre el $2 \%$ en Perú y Uruguay y el $13 \%$ en Chile - cifra inusual para este país, alcanzada gracias al éxito de "Stefan vs Kramer" (similar a lo que sucede en los países latinoamericanos, muy esporádicamente, cuando surge algún filme nacional que resulta éxito de taquilla, tal como sucedió, por ejemplo, con "Tropa de elite 2" en 
Revista Brasileira

de Estudos de

Cinema

e Audiovisual

Brasil, en el 2010; con "El viaje" y "El viaje 2" en Colombia, en 2010 y 2012, respectivamente, o con el "El secreto de sus ojos" en Argentina, en 2009, que representó por sí sola el $47 \%$ de los espectadores del centenar de estrenos nacionales de ese año).

Se toma el año 2012 porque 2013 fue un año poco común, con estrenos nacionales que rompieron récords históricos, especialmente en México, Perú y Venezuela -en menor medida, en la Argentina (con tres filmes nacionales que superaron el millón de espectadores) y Brasil (que alcanzó un market share de 18,6\%)-, dando porcentajes que no son representativos de los resultados de mercado para los filmes latinoamericanos en los últimos 25 años.

Un ejemplo de estas altas y bajas se puede apreciar en México: si en 2013 se estrenaron dos películas que rompieron los récords históricos de asistencia para un filme nacional ("No se admiten devoluciones" y "Nosotros los nobles"), en 2012 el mercado azteca se había presenciado uno de los market share más bajos para el cine nacional desde el año 2000 (4,8\%) aunque no tan lejos de los porcentajes de otros años, con un rango que varía entre el 4,3\% y el 7,6\% -salvo los años 2000, 2001 y 2002, con los éxitos de "Amores perros", "Y tu mamá también" y "El crimen del Padre Amaro", donde el cine nacional llegó a alcanzar el $8,9 \%, 8,5 \%$ y el $11,1 \%$, respectivamente.

Por otro lado, una buena manera de apreciar la participación de las películas nacionales en sus respectivos mercados es dividir la cantidad de espectadores que fueron a ver cine local por la cantidad de estrenos nacionales. 


\section{América Latina (2012) - Cantidad de espectadores por estreno nacional}

\begin{tabular}{|c|c|c|}
\hline$\#$ & País & $\begin{array}{c}\text { Cantidad de espectadores por filme nacional } \\
\text { estrenado comercialmente }\end{array}$ \\
\hline 1 & Brasil & 187.683 \\
\hline 2 & México & 162.687 \\
\hline 3 & Colombia & 161.905 \\
\hline 4 & Venezuela & 113.077 \\
\hline 5 & Chile & 95.385 \\
\hline 6 & Perú & 77.500 \\
\hline 7 & Argentina & 26.818 \\
\hline 8 & Uruguay & 4.118 \\
\hline
\end{tabular}

Fuente: Elaboración propia basada en datos del Incaa, Imcine, Ancine, CNCA, CNAC, Conacine, Dirección de Cinematografía (Colombia), Rentrak, Filme-B.

\section{América Latina (2007) - Cantidad de espectadores por estreno nacional}

\begin{tabular}{|c|c|c|}
\hline$\#$ & País & $\begin{array}{c}\text { Cantidad de espectadores por filme nacional } \\
\text { estrenado comercialmente }\end{array}$ \\
\hline 1 & México & 311.628 \\
\hline 2 & Colombia & 206.000 \\
\hline 3 & Venezuela & 166.667 \\
\hline 4 & Brasil & 132.179 \\
\hline 5 & Chile & 78.333 \\
\hline 6 & Uruguay & 74.000 \\
\hline 7 & Perú & 62.500 \\
\hline 8 & Argentina & 33.763 \\
\hline
\end{tabular}

Fuente: Elaboración propia basada en datos del Incaa, Imcine, Ancine, CNCA, CNAC, Conacine, Dirección de Cinematografía (Colombia), Nielsen, Filme-B, Deisica. 
De esta manera, se puede apreciar que cinematografías que son consideradas exitosas en su país - como suele verse a Argentina más allá de sus fronteras -, en realidad se ubican en los últimos lugares de este "ranking", mientras que cinematografías en recuperación -como la mexicana o brasileña-, o que ha ido consolidándose lentamente durante la última década - como la colombiana o venezolana-, se ubican en los primeros lugares.

Para tratar de comprender mejor el caso argentino, muchas veces sobrevalorado, vayamos al análisis de mercado del año $2012^{6}$ : de los 132 estrenos comerciales locales, ninguna película alcanzó un millón de espectadores cifra que varios blockbusters de Hollywood superan cada año en este país; la última vez que un filme nacional superó el millón de espectadores fue en 2009, con "El secreto de sus ojos". A su vez, dos filmes argentinos convocaron el $50 \%$ de todos los espectadores que fueron a ver cine nacional en este país en 2012, mientras que sólo ocho filmes nacionales superaron los 100.000 espectadores, y 75 no llegaron a convocar 2000 espectadores cada uno (33 películas ni siquiera fueron vistas por 500 espectadores y una docena de estrenos argentinos no pudieron convencer ni a 100 personas de que las vean...) Estos porcentajes se vienen repitiendo en Argentina desde hace muchos años. ${ }^{7}$

\section{Filmes latinoamericanos no nacionales}

En el caso de películas iberoamericanas no nacionales, el panorama es peor: la oferta y el consumo de éstas se ubican entre el $0,02 \%$ y el $2 \%$ - salvo la presencia de algún éxito excepcional, generalmente distribuído por alguna major norteamericana (GONZÁLEZ, 2012: 126).

La circulación de películas iberoamericanas al interior de la región es muy limitada, de tal modo que se estrenan en número reducido en los distintos

\footnotetext{
${ }^{6}$ Insistimos con que se toman los números de 2012, puesto que este año es más representativo -con respecto a los resultados de mercado de la última década- que 2013 (un año atípico).

${ }^{7}$ Elaboración propia basada en datos del Incaa, de las consultoras Rentrak, Ultracine, de Deisica y de medios especializados.
} 
Revista Brasileira

de Estudos de

Cinema

e Audiovisual

países, variando entre 3 y 20 estrenos anuales, dependiendo del mercado (GONZÁLEZ, 2012: 127).

Uruguay tiene una "alta" cantidad de filmes iberoamericanos exhibidos en sus salas comerciales, debido a la tradición cinéfila de su público - si se contaran las exhibiciones en los variados espacios alternativos existentes en el país, sobre todo en Montevideo (destacándose una entidad señera como la Cinemateca Uruguaya), el número de estrenos iberoamericanos registrados en la presente investigación se duplicaría.

En Brasil también existe una destacada red de salas de "cine arte", en especial en Rio de Janeiro, São Paulo y Porto Alegre, que es donde se exhiben mayormente los filmes iberoamericanos.

Tomando el promedio de los últimos años, el $40 \%$ de los filmes iberoamericanos estrenados en los países analizados fueron argentinos. Esta importante presencia de los filmes argentinos en toda la región puede explicarse porque el país sudamericano es el que más largometrajes realiza y también el que más coproduce - lo hace prácticamente con todos los países del subcontinente-, amén de su tradición fílmica de décadas, presente en el imaginario del público latinoamericano (GONZÁLEZ, 2012: 99).

Por su parte, un cuarto de los estrenos iberoamericanos correspondió en la década pasada a películas españolas; estos filmes son los que recaudan más, en comparación con los filmes latinoamericanos, debido a que se suelen estrenar los "tanques" de esa filmografía (El laberinto del fauno, Rec, Planet 51 , entre otros).

Las películas mexicanas representaron el $16 \%$ de los filmes iberoamericanos estrenados durante la última década (GONZÁLEZ, 2012: 127). Esto muestra cómo el esfuerzo del país azteca en incrementar su producción va rindiendo sus frutos -amén de que, como en el caso argentino, la cinematografía mexicana posee una importante tradición en toda América Latina (las películas clásicas mexicanas todavía se ven en la televisión de varios países de la región, algo que no sucede con cinematografías de otros países). 
Revista Brasileira

de Estudos de

Cinema

e Audiovisual

\section{Políticas públicas cinematográficas en América Latina}

La conformación y el desarrollo de la actividad cinematográfica y audiovisual sólo puede llevarse a cabo con el firme apoyo del Estado, debido a las altas y riesgosas inversiones necesarias que este sector requiere, en un marco de concentración oligopólica de la distribución y la exhibición -básicamente, en manos de las majors (Buena Vista, UIP, Warner, Fox, Sony), o de grandes empresas asociadas a éstas - , amén de los - relativamente - reducidos mercados.

Esto es cierto en todo el mundo, a excepción de los Estados Unidos, China y la India, países que cuentan con un enorme mercado interno que hace posible la amortización de sus productos audiovisuales -e inclusive en el caso de los Estados Unidos, el sector cinematográfico se beneficia de distintos apoyos estatales (al contrario de lo que el sentido común indica), tales como subsidios directos (desgravaciones y exenciones fiscales, pagos diferidos, amortizaciones aceleradas) e indirectos (incontables estrategias y recursos políticas y económicos que presionan a nivel mundial en favor de sus propias empresas) (WASKO, 2003; GUBACK, 1980). En China el Estado también se encuentra presente a la hora de fomentar su cine nacional.

En América Latina, el neoliberalismo ortodoxo imperante (desregulación estatal, liberalización, privatización) desde las décadas de 1970 y 1980 (dependiendo del país) dio paso, a lo largo del decenio 2000-2010, a un renovado impulso de políticas públicas heterodoxas destinadas al estímulo del mercado interno, tanto a nivel general, como el ámbito del cine, en particular. Un nuevo "neofomentismo" tuvo lugar al interior de los distintos Estados latinoamericanos a lo largo de esta década, en contra de lo sucedido durante la década de 1990, cuando los cines latinoamericanos (en especial, Argentina, Brasil y México) vieron desmantelar la ayuda estatal al cine.

Durante la primera década del siglo XXI en toda América Latina fueron sancionándose legislaciones nacionales dedicadas al cine, como en Chile, Colombia, Venezuela, Ecuador, Panamá, Uruguay y Nicaragua. Con excepción 
de Paraguay y las Guayanas, todos los países de América del Sur y México ${ }^{8}$ poseen legislación nacional de fomento a la cinematografía ${ }^{9}$ y órgano rector de la actividad.

A nivel general, estas políticas públicas de fomento al cine en América Latina se basan en ayudas directas -sobre todo a la producción, aunque en algunos casos, también en la distribución, exhibición y promoción-, principalmente, a través de subsidios o créditos blandos. En algunos países los incentivos se extienden a otras actividades audiovisuales, como la producción y difusión de contenidos televisivos y audiovisuales -tal como sucede en Chile o en Colombia (en los últimos años, Brasil aprobó una ley de televisión paga que obliga a emitir contenido brasileño, buscando fomentar la producción nacional, mientras que en la Argentina se lanzaron programas específicos para producir contenidos destinados a la futura televisión digital).

Sin embargo, en la práctica, las políticas "neofomentistas" en América Latina se concentran mayoritariamente en la producción cinematográfica con el fin de potenciar el buen uso de la infraestructura disponible en cada país dedicada a esta actividad. Por otro lado, buscan aplicar incentivos fiscales para atraer la inversión, tanto del sector privado -como sucede, por ejemplo, en Brasil, Colombia y México - como de los propios contribuyentes del país a través de impuestos a las taquillas o de partidas provenientes del presupuesto nacional -como ocurre, de distintas maneras, en Argentina, Uruguay, Venezuela, Perú y Bolivia.

En la letra de las legislaciones latinoamericanas de fomento al cine se incluyen todos los eslabones de la cadena productiva, desde el desarrollo hasta la difusión y exhibición. A nivel general, las políticas públicas de fomento al cine en América Latina se basan en ayudas directas -sobre todo a la producción, aunque en algunos casos, también a la distribución, exhibición y promoción-,

\footnotetext{
8 En el caso de los países centroamericanos y caribeños, el fomento al cine es más endeble (exceptuando el caso cubano), basado principalmente en exenciones fiscales o en incentivos para la utilización de los escenarios naturales locales como escenarios para rodajes de producciones extranjeras.

${ }^{9}$ En algunos países, como Perú, Bolivia y Venezuela, existen debates al interior del sector para reformular sus respectivas leyes de cine.
} 
Revista Brasileira

de Estudos de

Cinema

e Audiovisual

principalmente, a través de subsidios o créditos blandos. En algunos países los incentivos se extienden a otras actividades audiovisuales, como la producción y difusión de contenidos televisivos y audiovisuales -tal como sucede en Chile o en Colombia (recientemente, en Argentina se lanzaron programas específicos para producir contenidos destinados a la futura televisión digital).

Una de las medidas más antiguas de protección -e inclusive, de promoción- de la producción cinematográfica a nivel mundial es la institución de la "cuota de pantalla" en las salas de cine -es decir, la reserva de un tiempo mínimo de programación anual o periódica en las salas de cine de un país, destinado a la exhibición obligatoria de filmes nacionales. A pesar de que las legislaciones de distintos países latinoamericanos contemplan la cuota de pantalla -como México, Chile, Perú-, sólo en Argentina, Brasil y Venezuela el Estado tiene una posición más activa con esta prerrogativa. En algunos casos, como en Chile, la televisión tiene la obligación efectiva de programar en sus pantallas cierta cantidad de películas nacionales.

\section{Los principales mecanismos de fomento al cine en América Latina}

Las distintas medidas de apoyo a la actividad cinematográfica fueron, y son muy importantes para mantener la producción cinematográfica en América Latina y los distintos países que realizan cine, en un contexto de creciente e intensa competencia global -con las majors hollywoodenses como protagonistas.

Las medidas más frecuentes de fomento al sector cinematográfico se dan en la producción, aunque también existen - pero en mucha menor medida- apoyos a la pre producción, a la post producción, la distribución y la exhibición, ayudas que no son homogéneas y varían entre la regulación, el mecenazgo y la promoción (HARVEY, 2005: 428).

Estas ayudas se basan en variados sistemas, principalmente constituídos por operaciones no reintegrables, como subsidios, adelantos sobre ingresos de taquilla y subvenciones de distintos tipos. En América Latina la mayor parte de las ayudas son selectivas, aunque también existen varias de carácter automático. 
Revista Brasileira

de Estudos de

Cinema

e Audiovisual

Por otro lado, también fueron y son muy utilizadas las políticas fiscales de exención impositiva para estimular la inversión de capitales privados, principalmente, en la producción cinematográfica - aunque también se han aplicado líneas en este sentido para la exhibición y otros eslabones de la cadena de valor. Se destacan los casos de Gran Bretaña, Canadá y, en América Latina, Puerto Rico, Brasil - con la sanción de las leyes "Rouanet" (1991) y del Audiovisual (1993) - y, desde 2003, Colombia - cuando se dio la aprobación de su ley de cine, que pone mucho énfasis en este tipo de ayudas.

Otras medidas no menos importantes son los sistemas basados en el otorgamiento de créditos a la actividad cinematográfica, un sector en donde el capital y la banca privada son poco propensos a atender - debido al alto riesgo inherente a esta actividad. Este tipo de ayudas se ofrecen en Francia, España, México, Argentina y Brasil, entre otros países.

En este breve compendio sobre ayudas al sector cinematográfico no puede faltar la "banca cinematográfica", es decir, experiencias en donde el Estado asume el rol de banquero de la actividad cinematográfica a través de líneas reintegrables de créditos, o la cobertura de riesgos a través de avales o garantías. Se destaca la experiencia francesa, la mexicana (entre 1947 y 1979), la brasileña (a través de Embrafilme, entre 1969 y 1990) y, en alguna medida, los sistemas español, portorriqueño y colombiano. Como se mencionó, en América Latina se destacó la actividad del Banco Cinematográfico de México; y en Italia descolla la Banca Nazionale del Lavoro, con su sección cinematográfica (HARVEY, 2005: 19).

\section{Intentos de políticas públicas regionales en Iberoamérica}

Desde hace más de dos décadas existen intentos para articular legislaciones, políticas y acciones gubernamentales de fomento al cine y al audiovisual a nivel regional. Los antecedentes más importantes son la Conferencia lberoamericana de Autoridades Cinematográficas (Caci) y la Reunión Especializada de Autoridades Cinematográficas y Audiovisuales del Mercosur (Recam). 
Revista Brasileira

de Estudos de

Cinema

e Audiovisual

\section{La Conferencia de Autoridades Cinematográficas de lberoamérica (Caci)}

En noviembre de 1989 los representantes de distintos gobiernos iberoamericanos firmaron en Caracas tres importantes documentos dirigidos a promover el cine iberoamericano: el Convenio de Integración Iberoamericana, el Acuerdo Latinoamericano de Coproducción Cinematográfica y el Acuerdo para la Creación del Mercado Cinematográfico Latinoamericano. A partir de estas firmas nació la Conferencia de Autoridades Cinematográficas de Iberoamérica (Caci) -luego se le agregó el término "audiovisual" al "cinematográfico", cambiando la sigla a Caaci. Sin embargo, desde hace un par de años, el nombre de este organismo volvió a remitir solamente a lo cinematográfico (volviendo a la sigla Caci).

En octubre de 1995, la V Cumbre Iberoamericana de Jefes de Estado y de Gobierno, celebrada en Bariloche, Argentina, aprobó de un programa de fomento de la industria audiovisual iberoamericana que sería el único que alcanzaría cierta trascendencia en el sector: Ibermedia. Este programa se lanzó buscando dar impulso "a la distribución, promoción, formación, a coproducciones y al desarrollo de proyectos". ${ }^{10}$

Ibermedia, cuya primera etapa abarcó desde enero de 1998 hasta diciembre de 2002, se constituyó inicialmente con la adhesión institucional y el aporte monetario de nueve países: Argentina, Brasil, Colombia, Cuba, España, México, Portugal, Uruguay y Venezuela. Luego, a lo largo de los años, se irían incorporando Chile, Perú, Ecuador, Puerto Rico, Costa Rica, República Dominicana, Panamá y Paraguay.

También es de mencionar el programa DocTV Iberoamérica - que se encuentra enmarcado en la $\mathrm{Caci}-$, integrado por las agencias nacionales de cine y las televisoras públicas-estatales de casi todos los países de la región, cuyo objetivo es fomentar la creación y difusión de documentales latinoamericanos.

De manera paradójica el nacimiento de la Caci, y posteriormente, de lbermedia, se dio en años en los que la política neoliberal de desguace del Es-

\footnotetext{
${ }^{10}$ Reunión Informal de Ministros y de Responsables de las Políticas Culturales en Iberoamérica. Madrid, 25 y 26 de junio de 1997.
} 
tado y de baja en las medidas de protección y fomento a distintos sectores productivos ocurría en la mayor parte de América Latina, con las consecuencias de desmantelar las industrias locales y facilitar el ingreso irrestricto de bienes y servicios extranjeros -especialmente, de compañías transnacionales. Todas las cinematografías que tenían algún respaldo estatal tuvieron severos recortes y hasta disolución de las medidas de fomento estatales, dejándolas al borde de la desaparición -especialmente, durante el primer lustro de la década de 1990.

\section{La Reunión Especializada de Autoridades Cinematográficas y Audiovisuales del Mercosur (Recam)}

En marzo de 1995 se realizó en Buenos Aires la Primera Reunión Especializada de Cultura del Mercosur. Allí se conformaron siete Comisiones Técnicas para tratar distintos aspectos de la cultura subregional; una de ellas se dedicó al sector de las industrias culturales. Desde ese momento comenzaron a realizarse distintas reuniones periódicas, dentro de las cuales tuvo un lugar destacado el sector cinematográfico y audiovisual.

Sin embargo, hubo que esperar hasta diciembre de 2003 para que el Grupo Mercado Común del Mercosur - uno de los más altos órganos decisorios de esta instancia supranacional - creara la Reunión Especializada de Autoridades Cinematográficas y Audiovisuales (Recam), invocando el Tratado de Asunción y el Protocolo de Ouro Preto-ambos, documentos fundantes del Mercosur-, además del Protocolo de Integración Cultural del Mercosur, el Protocolo de Montevideo sobre Comercio de Servicios y las Decisiones del Consejo del Mercado Común.

Así, el GMC acordó:

"crear la Reunión Especializada de Autoridades Cinematográficas y Audiovisuales (Recam), con la finalidad de analizar, desarrollar e implementar mecanismos destinados a promover la complementación e integración de dichas industrias en la región, la armonización de políticas públicas del sector, la promoción de la libre circulación de bienes y servicios cinematográficos en la región y la armonización de los aspectos legislativos" (GMC, 2003). 
Revista Brasileira

de Estudos de

Cinema

e Audiovisual

Pocos meses después, en marzo de 2004, la Recam realizó su primera reunión ordinaria. Desde entonces forman parte de la Recam, como países miembros, Argentina (Incaa), Brasil (Secretaría del Audiovisual y Ancine), Paraguay (Dirección Nacional del Audiovisual) y Uruguay - Instituto Nacional del Audiovisual (INA), que desde 2008 se llama Instituto del Cine y el Audiovisual del Uruguay (Icau). Y como países asociados se encuentran Bolivia - Consejo Nacional del Cine (Conacine)-, Chile - Consejo Nacional del Arte y la Industria Audiovisual - y Venezuela - Centro Nacional Autónomo de Cinematografía (CNAC) -; desde 2012 Venezuela es país miembro - en el contexto de similar incorporación de Venezuela al Mercosur, luego de la suspensión de Paraguay a partir del "golpe institucional" contra el presidente Fernando Lugo. En 2011 Ecuador se sumó a la Recam como país asociado, a través del Consejo Nacional de Cinematografía (CNCine).

Aunque el nombre de este organismo refiere tanto a cine como a "audiovisual”, en lo concreto, sólo el ámbito cinematográfico intentó tener cabida en la Recam: nunca hubo un acercamiento serio ni participación sostenida de autoridades relacionadas con el ámbito televisivo u otro relacionado con el quehacer audiovisual no cinematográfico.

\section{Esbozo de balance de las iniciativas de integración cinematográfica}

La cooperación audiovisual depende de la cooperación política, económica y cultural de los gobiernos y espacios regionales en donde se inserta. Así, mientras de éstas administraciones suelen centrarse en temáticas económicas, comerciales, financieras y políticas, la cultura suele quedar relegada.

En el ámbito cultural se observa que los organismos regionales existentes suelen actuar sin coordinación, solapadamente, superponiéndose. A su vez, los acuerdos que se toman suelen ser meras declaraciones de buenas intenciones que no son vinculantes - la Carta Cultural Iberoamericana es un buen ejemplo de ello: las decisiones tomadas en los organismos regionales de cultura escasamente se trasladan a las normativas nacionales. En el ámbito au- 
Revista Brasileira

de Estudos de

Cinema

e Audiovisual

diovisual, esta deficiencia es aún mayor -la nula coordinación entre la Caci y la Recam, es un ejemplo de ello (son varios los países que pertenecen a ambas instancias, con repetidos objetivos y declaraciones de intenciones similares, pero que no dialogan ni se potencian entre sî).

Por otra parte, se continúa imponiendo una visión nacional que busca imponer sus intereses por sobre el resto: reuniones que debieran ser de cooperación terminan siendo feroces competencias, en donde la fortaleza de los países más grandes termina imponiéndose.

Esto es lo que sucede en las distintas reuniones de lbermedia -el programa regional más exitoso en lo que hace al audiovisual-, según relatan varias autoridades presentes en esas reuniones ${ }^{11}$ : allí, el éxito es medido por sus participantes por la cantidad de proyectos nacionales seleccionados y premiados, y sobre todo, por la suma de apoyos monetarios recibidos en relación a la cuota aportada. A su vez, esto es así porque - merced a las limitaciones presupuestarias para el sector - las asociaciones nacionales de productores y realizadores interpelan fuertemente a los representantes nacionales de sus agencias nacionales de cine: Ibermedia termina perdiendo la perspectiva, y finalmente se reduce a reuniones con duras negociaciones para tratar de obtener los mayores recursos posibles, más que un lugar de reflexión y acción sobre la construcción y fortalecimiento de un espacio audiovisual regional, con su valor agregado a partir de sinergias y potencialidades que vayan más allá de un mero agregado de realidades nacionales y tengan en cuenta una mayor integración, circulación y espacio común de producción, conocimiento y consumo.

La mayoría de los recursos de lbermedia se destinan a la coproducción. La diferencia con el resto de áreas del programa - distribución, el desarrollo de proyectos y la formación - es bastante significativa. A su vez, Argentina, Brasil, México, Chile y España son los países con más proyectos apoyados - es decir, los países con mayores recursos -, mientras que un porcentaje importante de los recursos se destina a proyectos que no se concretan y menos

\footnotetext{
${ }^{11}$ Entrevistas personales realizadas con carácter confidencial a algunos funcionarios y autoridades nacionales de cine presentes en algunas de esas reuniones (entrevistas realizadas en Córdoba, Argentina, 2006; México, 2008; Bogotá, 2011; Río de Janeiro, 2011; Buenos Aires, 2012; y Madrid, 2013).
} 
del $30 \%$ de los filmes resultantes de este programa se estrenan allende las fronteras de su(s) país(es) productor(es) (GONZÁLEZ, 2012: 103).

Otro aspecto importante a tener en cuenta es la profesionalización de los funcionarios de estos organismos públicos.

La Caci tiene una Secretaría Ejecutiva en Caracas, ejercida por el presidente de la agencia venezolana de cine -el Consejo Nacional de Cinematografía (CNAC) - , y a su vez, su principal programa Ibermedia tiene en su oficina de Madrid a profesionales con post grados o gestores culturales con experiencia. El caso de la Reunión Especializada de Autoridades Cinematográficas y Audiovisuales es bien diferente.

Aunque la Recam posee una secretaría técnica, esta institución - que figura oficialmente en el organigrama del Mercosur - ha estado comandada en la práctica por la Argentina, bajo la influencia de su Agencia Nacional de Cine -el Instituto Nacional de Cine y Artes Audiovisuales (Incaa).

En casi diez años de funcionamiento la Recam no ha conseguido ningún logro sustentable e importante: el que pudo haber sido su mayor logro, el Observatorio del Mercosur Audiovisual -constituído por el reconocido investigador hispano-argentino Octavio Getino-, quedó congelado en 2008 ante la salida de la Recam por parte de Getino debido a discrepancias políticas.

En 2003, en la etapa de conversaciones para crear la Recam entre las distintas Agencias Nacionales de Cine del Mercosur, Argentina y Brasil firmaron un acuerdo de codistribución - uno de los primeros en el mundo- para fomentar el estreno de filmes argentinos en Brasil y brasileños en la Argentina -seis por año en cada país - con apoyo de las respectivas Agencias Nacionales de Cine. Sin embargo, y aunque se incrementó momentáneamente la oferta de estos filmes en ambos mercados, la calidad de los lanzamientos y la respuesta del público fue pobre en Argentina, en donde la ejecución de este convenio dejó mucho que desear por parte de los funcionarios del Incaa' ${ }^{12}$ se hizo un pobre

\footnotetext{
${ }^{12}$ Argentina es un país que no tiene examen de ingreso para ingresar a la función pública, por lo que la enorme mayoría de los funcionarios -inclusive secretarios de Estado y hasta ministros- apenas tienen educación secundaria. Casi la totalidad de los funcionarios públicos ingresan por contactos políticos o por tener un familiar o conocido con poder trabajando en el Estado. A su vez, los funcionarios comienzan a trabajar sin tener conocimiento alguno para el cargo que fueron asignados. La única
} 
Revista Brasileira

de Estudos de

Cinema

e Audiovisual

seguimiento a la comercialización, al marketing y a la difusión de las películas brasileñas -en el lado brasileño se manejaron más profesionalmente. Por ello, tras dos años de intentos, Brasil decidió dejar de aplicar el acuerdo.

En 2004, la Recam había intentado avanzar en un Sello Cultural del Mercosur dedicado al audiovisual, pero ante falta de personal capacitado que trabajara mancomunadamente con Cancillerías, Ministerios de Economía, Hacienda y Aduanas, entre otras instituciones, el proyecto quedó en la nada. Tampoco fructificaron ideas sobre una "cuota de pantalla regional" y sobre un "certificado de nacionalidad" regional para las películas de países miembros del Mercosur.

A su vez, en 2009 la Recam firmó un convenio con la Unión Europea por un monto de 1,86 millón de euros para reforzar el espacio cinematográfico mercosureño $-1,5$ millón de euros aportados por la Unión Europea, y 360 mil euros aportados por la Recam (a través de los aportes de los países integrantes). El programa para llevar a cabo este convenio se denominó Programa Mercosur Audiovisual (PMA) e iba a durar tres años (GMC, 2009). Se establecieron objetivos que, a abril de 2014, no se cumplieron.

Uno de los principales objetivos del Programa Mercosur Audiovisual era reforzar el observatorio; cuando se comenzó a implementar, fue lo primero que se dio de baja.

Otro de los objetivos importantes era crear una red de unas 30 salas digitales en todo el Mercosur para proyectar exclusivamente películas de los países que conforman la Recam; desde 2008 se viene anunciando que "en breve" se comenzaría a implementar (Mercosur Radio, 2008; UPI, 2012). A abril de 2014 todavía no se construyó ni una sala de esa red.

Otro de los objetivos del PMA era la realización de estudios e investigaciones. No se hicieron públicas las convocatorias, a pesar de que la Unión Europea así lo mandaba. El organismo europeo también pedía que los consultores tuvieran -mínimamente - título universitario y experiencia en el tema sobre el que iban a investigar: las investigaciones terminaron recayendo en produc-

excepción dentro del Estado argentino es el ámbito de Cancillería: allí sí existen duros exámenes para acceder a los cargos diplomáticos -aunque durante el gobierno kirchnerista, también se está dejando a un lado a los funcionarios de carrera para reemplazarlos por funcionarios sin experiencia puestos por afinidad política. 
Revista Brasileira

de Estudos de

Cinema

e Audiovisual

tores afines a la jefatura del Incaa y hasta en empleados de ese organismo argentino que no tenían título universitario ni experiencia en la temática-según la Unión Europea, ningún empleado de cualquier Agencia Nacional de Cine del Mercosur podía haberse presentado; por este tema, existe una denuncia ante la Oficina Anti-fraude de la Unión Europea. ${ }^{13}$

En 2009, año de la firma del convenio entre la Recam y la Unión Europea, se anunció que el Programa Mercosur Audiovisual iba a comenzar a implementarse el 1 de julio de ese año (GMC, 2009). Sin embargo, el inicio de la implementación se dio recién en febrero de 2011 (PMA, 2011) - momento en el que tendría que haber estado transcurriendo el penúltimo año de implementación.

Hasta abril de 2014 lo único concreto que se realizó fueron talleres y encuentros dispersos -especialmente a partir de 2012, cuando la Unión Europea comenzó a pedir a la Recam que concretara el Programa Mercosur Audiovisual, que debería haber concluído a mediados de 2012.

\section{A modo de conclusión}

Las distintas Agencias Nacionales de Cine latinoamericanas casi no han variado sus políticas de fomento, volcadas casi exclusivamente a la producción, con criterios que no varían mucho de las de hace medio siglo.

La presencia de los filmes nacionales y latinoamericanos en las pantallas es ínfima: $5 \%$ promedio para las películas nacionales y $0,5 \%$ promedio para los filmes latinoamericanos -en este último caso, vistos casi exclusivamente por pocos miles de espectadores de buen nivel económico y educativo (es decir, una reducida minoría dentro de la población de la región).

Sin embargo, en la televisión de América Latina los contenidos locales son mayoría, en un medio en que el habitante latinoamericano mira entre tres y cuatro horas diarias, a diferencia de la hora y media que, en promedio, dedica cada dos años para ver una película en el cine, o de los 16 años que -según marca el promedio - transcurren para que elija ver una película nacional en

${ }^{13}$ Denuncia realizada ante la Oficina Europea de Lucha contra el Fraude (OLAF) el 16 de julio de 2012. 
las salas... No obstante, la presencia del cine latinoamericano en la televisión es prácticamente nula.

Desde hace muchos años se vienen realizando periódicamente llamadas a plantear unas políticas integrales del audiovisual, que engloben al cine, a la televisión y a las nuevas tecnologías audiovisuales. Existen casos aislados, muy voluntariosos, loables y esforzados, impulsados en ocasiones por profesionales probos y bien intencionados, como el mencionado Programa Ibermedia, DocTV Iberoamérica, TAL TV o de la fallida Reunión Especializada de Autoridades Cinematográficas y Audiovisuales del Mercosur (Recam), amén de distintos foros y encuentros que se crean y se esparcen por toda América Latina convocados por productores, realizadores, documentalistas, exhibidores, funcionarios y distintos agentes del sector.

Sin embargo, nada concreto ha salido de ello - excepto algunas medidas en pro de la cooperación cinematográfica ${ }^{14}$ (siendo lbermedia la que mayores logros ha conseguido) y de la televisión educativa y documental (sin mayor repercusión en la industria ni en las audiencias).

A pesar de variados esfuerzos, declaraciones y romantizaciones, el cine latinoamericano continúa en su laberinto, situación incentivada por el desconocimiento mutuo existente entre nuestras variadas cinematografías y sus realidades y que mina la posibilidad de acometer una necesaria integración del séptimo arte latinoamericano, para potenciar sinergias, capacidades y públicos.

\section{Fuentes estadísticas}

Agencia Nacional de Cinema (Brasil), Consejo de la Cultura y las Artes (Chile), Consejo Nacional Autónomo de Cinematografía (Venezuela), Consejo Nacional de Cinematografía (Perú), Dirección de Cinematografía (Colombia), Instituto Nacional de Cine (México), Instituto Nacional de Cine y Artes Audiovi-

\footnotetext{
${ }^{14}$ Un claro ejemplo en este sentido es el caso del área francófona, con un foro institucionalizado de televisoras de distintos países de habla francesa, existente desde hace años.
} 
suales (Argentina), Deisica, Filme-B, Media Salles, Nielsen-Rentrak, Ultracine, empresas exhibidoras.

Principales sites de organismos consultados

www.programaibermedia.com

www.recam.org 
Revista Brasileira

de Estudos de

Cinema

e Audiovisual

\section{Bibliografía}

BALIO, Tino. Hollywood as a Modern Business Enterprise, 1930-1939. Nueva York: Scribners, 1993.

CASTAÑEDA LÓPEZ, Liliana. "Agentes del sector cinematográfico y la diversidad cultural en Colombia" en: Comunicación y sociedad. Número 15, enero-junio de 2011, pgs. 143 a 168.

GETINO, Octavio. Cine iberoamericano: los desafíos del nuevo siglo. San José de Costa Rica: Editorial Veritas, 2005.

"Sin imágenes dónde mirarse" en Le Monde Diplomatique, edición Cono Sur, número 16, octubre de 2000.

GONZÁLEZ, Roque. "Cine latinoamericano: entre la pantalla de plata y las pantallas digitales (2000-2009)". In: Octavio GETINO (coordinador), América Latina: producción y mercados en la primera década del siglo XX. Buenos Aires: Ciccus, 2012, pgs. 61 a 182.

Cine latinoamericano y nuevas tecnologías audiovisuales. La Habana: Fundación del Nuevo Cine Latinoamericano, 2011.

Grupo Mercado Común del Mercosur (GMC). Resolución No 49: Reunión Especializada de Autoridades Cinematográficas y Audiovisuales del Mercosur. Reunión LII. Montevideo, 10 de diciembre de 2003.

Resolución DCI/ALA/020-297, 2009.

GUBACK, Thomas. La industria internacional del cine [1969]. Madrid: Fundamentos, 1980. 
HARVEY, Edwin. Política y financiación pública de la cinematografía. Países iberoamericanos en el contexto internacional. Madrid: Fundación Autor, 2005.

LAY, Tonatiuh. Análisis del proceso de la iniciativa de Ley de la Industria Cinematográfica de 1998. Guadalajara: Editorial de la Universidad de Guadalajara, 2005.

Mercosur Radio. "La UE destina 1,5 millones para potenciar el sector audiovisual en Mercosur", 22 de setiembre de 2008. Disponible en: http:// www.mercosurradio.com.ar/joomla/index.php?option=com_content\&view=a rticle\&id=203: cultura\&catid=1:latest-news\&ltemid=50. Ultimo acceso: 20 de abril de 2014.

MILLER, Toby y George YÚDICE, Política cultural. Barcelona: Gedisa, 2004.

PENDAKUR, Manjunath, Canadian Dreams and American Control. The Political Economy of Canadian Film Industry. Detroit: Wayne State University Press, 1990.

Programa Mercosur Audiovisual (PMA)-Recam. Documento interno: nota número 14/11 del 9 de febrero de 2011.

SÁNCHEZ RUIZ, Enrique. "Diversidad y concentración en el audiovisual iberoamericano". In: Carlos DEL VALLE, Francisco Javier MORENO y Francisco SIERRA (coord.), Políticas de comunicación y ciudadanía cultural iberoamericana. Barcelona: Gedisa, 2012, pgs. 63 a 88.

Unesco, "Analysis of the UIS Survey on Feature Film Statistics", informe de prensa, Montreal, 2007.

United Press International. "Uruguay coordinará red de audiovisuales del Mercosur", 17 de diciembre de 2012. Disponible en: http://espanol.upi. 
com/Noticias-destacadas/2012/12/17/Uruguay-coordinar\%C3\%A1-red-deaudiovisuales-del-Mercosur/UPI-26221355795503/ Ultimo acceso: 27 de agosto de 2013.

Variety, "International Profile: Argentina Offers Reminder of Basic Business Model", 6 de abril de 2013. Disponible en: http://variety.com/2013/biz/global/ international-profile-argentina-1200331677/ Ultimo acceso: 29 de abril de 2014.

Wasko, Janet. How Hollywood Works. Londres: Sage, 2003.

"The Death of Hollywood: Exaggeration or Reality?". In: Janet WASKO, Graham MURDOCK y Helena SOUSA (eds.), The Handbook of Political Economy of Communications. Londres: Blackwell, 2011, pgs. 307 a 330. 